\title{
Isotope Studies in Oxidation of Propane over Vanadium Oxide
}

\author{
Pierre Kube, ${ }^{[a]}$ Benjamin Frank, ${ }^{[a, b]}$ Robert Schlögl, ${ }^{[a]}$ and Annette Trunschke* ${ }^{\star[a]}$ \\ Dedication ((optional))
}

\begin{abstract}
The oxidation of propane has been studied over silicasupported vanadium oxide and polycrystalline, bulk MoVTeNb oxide with M1 structure. Temperature-programmed reaction experiments were performed, and the reactivity of propane molecules labeled with deuterium and ${ }^{13} \mathrm{C}$, respectively, was analyzed under steady-state conditions. The measurement of kinetic isotope effects reveals fundamental differences in the activation of propane over the two catalysts. The reaction network of consecutive and parallel reactions of the formed propylene is comparable. However, oxygen insertion into the $\mathrm{CHO}$ group of acrolein under formation of acrylic acid is faster over M1 than oxidation at the $\mathrm{CH}_{2}$ group and decarbonylation to acetaldehyde. In contrast, the latter process is preferred over silicasupported vanadium oxide resulting in lower selectivity to unsaturated oxygenates.
\end{abstract}

\section{Introduction}

The activation of $\mathrm{C}-\mathrm{H}$ bonds in small alkane molecules has been widely investigated in chemistry in general and specifically in heterogeneous catalysis with the intent to use the large natural gas reserves of our planet economically in the synthesis of chemicals. ${ }^{[1]}$ Theoretical and kinetic studies of selective oxidation and oxidative dehydrogenation of alkanes with molecular oxygen over metal oxide catalysts disclosed an intricate network of parallel and consecutive reactions that limits the selectivity towards desired olefins or unsaturated oxygenates. ${ }^{[2]}$ In kinetic studies of oxidative dehydrogenation $(\mathrm{ODH})$ of propane over supported vanadium oxide catalysts the reaction network is, however, usually condensed and presented as a triangle (Scheme 1, black symbols and lines). ${ }^{[3]}$ Albeit in traces, oxygenates have been detected in the gas phase, revealing that a more complex underlying network (Scheme 1, blue symbols) has implications on the selectivity towards the main products propene, $\mathrm{CO}$, and $\mathrm{CO}_{2}{ }^{[4]}$ The selectivity to propene is highly dependent on catalyst composition (nature of support, promoters and modifiers, vanadium oxide loading), catalyst structure (molecular structure of vanadium oxide surface species, degree of oligomerization, degree of hydroxylation, texture of catalyst or support) and reaction conditions (partial pressures, temperature, steam content). ${ }^{[5]}$ Detailed knowledge of the reaction network and its dependence on catalyst structure is the key to control

[a] P. Kube, Dr. B. Frank, Prof. Dr. R. Schlögl, Dr. A. Trunschke Department of Inorganic Chemistry

Fritz-Haber-Institut der Max-Planck-Gesellschaft

Faradayweg 4-6, 14195 Berlin (Germany)

E-mail: trunschke@fhi-berlin.mpg.de

[b] Current address of Dr. B. Frank

BasCat - UniCat BASF Joint Lab

TU Berlin, Sekr. EW K 01

Hardenbergstr. 36, D-10623 Berlin (Germany)

Supporting information for this article is given via a link at the end of the document. selectivity. But so far, research was mainly focused on the first supposedly rate determining step (RDS) that comprises hydrogen abstraction under formation of a propyl radical (Scheme 1, red) and a hydroxyl group. Analyses of kinetic isotope effects (KIE) over supported vanadium oxide revealed that hydrogen in methylene position is abstracted first affecting the rate of the overall reaction. ${ }^{[6]}$ Consequently, the barrier of the first step controls activity, although quantum chemical calculations of the (010) surface of $\mathrm{V}_{2} \mathrm{O}_{5}$ indicated that subsequent steps such as the regeneration of the active site by dehydroxylation might exhibit high barriers as well. ${ }^{[7]}$

In general, selectivity is affected by favouring specific pathways compared to others. High barriers in the multistep pathways to carbon dioxide, i.e., deceleration of the corresponding reaction(s), may then result in increased selectivity to propene. Herein we investigate the reaction network in propane oxidation over bulk mixed MoVTeNb oxide (M1) and a silica-supported (mesoporous silica SBA-15) vanadium oxide monolayer model catalyst (6V/SBA-15) by temperatureprogrammed reaction and steady-state experiments using isotope labelled reactants. The reaction conditions are limited to fat, dry feed $\left(\mathrm{C}_{3} \mathrm{H}_{8} / \mathrm{O}_{2} / \mathrm{He}=10 / 5 / 85\right)$ and low propane conversion. Under these reaction conditions the selectivity to undesired carbon oxides is higher over silica-supported vanadium oxide compared to $M 1 .{ }^{[4]}$ Factors that determine selectivity in the oxidation of short-chain alkanes over vanadium oxide catalysts are discussed based on the comparative analysis of the reaction network over the two catalysts.

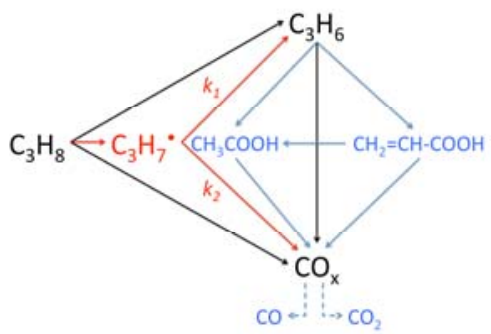

Scheme 1. Simplified reaction network in oxidative dehydrogenation of propane over vanadium oxide catalysts (black symbols) and minimum extension based on detected gas phase intermediates ${ }^{[4,8]}$ (blue symbols) and the supposed $\mathrm{C}_{3} \mathrm{H}_{7} \cdot$ surface / gas phase intermediate (red).

\section{Results and Discussion}

Oxidative dehydrogenation of propane was performed in temperature-programmed experiments by increasing the temperature stepwise (Fig. 1). Each individual data point presented in Figs. $1 a-b$ is the average of 3-5 measurement points in steady state at the corresponding reaction temperature. Steady state confirms that the corresponding products are formed catalytically. The reaction products in the gas phase were 
analysed by gas chromatography. Conversion and selectivity as a function of temperature are shown in Fig. S1. A multitude of products was observed over both catalysts. The types of products are the same over M1 and 6V/SBA-15, with the exception of propionic acid that was only detected over 6V/SBA-15. However, the relative concentrations and the temperatures, at which the individual products appear first, differ.

Propene is the first product detectable over both catalysts at a temperature as low as $120^{\circ} \mathrm{C}$. The low temperature clearly indicates that $\mathrm{C}-\mathrm{H}$ activation is not the major problem on vanadium oxide catalysts. At higher temperature $\left(160-180^{\circ} \mathrm{C}\right)$ acetone appears as second product, whereas the concentration of propene and acetone is higher over M1 compared to 6V/SBA15. It is not possible to conclude from the present experiments whether acetone and propene are formed via the same iso- propoxide surface intermediate or whether iso-propoxide as probable precursor of acetone is formed after re-adsorption of propene. It has to be noted at this point that the sensitivity of the thermal conductivity detector (TCD) used for analysis of the carbon oxides is lower compared to the sensitivity of the flame ionization detector (FID) applied for analysis of hydrocarbons and oxygenates. Consequently, the fact that no carbon oxides are observed below $200^{\circ} \mathrm{C}$ when acetone is already formed does not necessarily mean that acetone is no precursor for $\mathrm{CO}_{2},{ }^{[9]}$ because $\mathrm{CO}_{2}$ is only detectable at a minimum concentration of $1 \mathrm{ppm}$. On the other hand, it has been shown that acetone is quite stable under oxidizing conditions over MoVTeNb oxide. ${ }^{[8]} \mathrm{CO}_{2}$ is detected first over $\mathrm{M} 1$ at $250^{\circ} \mathrm{C}$. In contrast, $\mathrm{CO}_{2}$ appears on $6 \mathrm{~V} / \mathrm{SBA}-15$ with a temperature offset of only $20 \mathrm{~K}$ with respect to acetone already at $200^{\circ} \mathrm{C}$ and might consequently stem more likely from total oxidation of acetone as well.
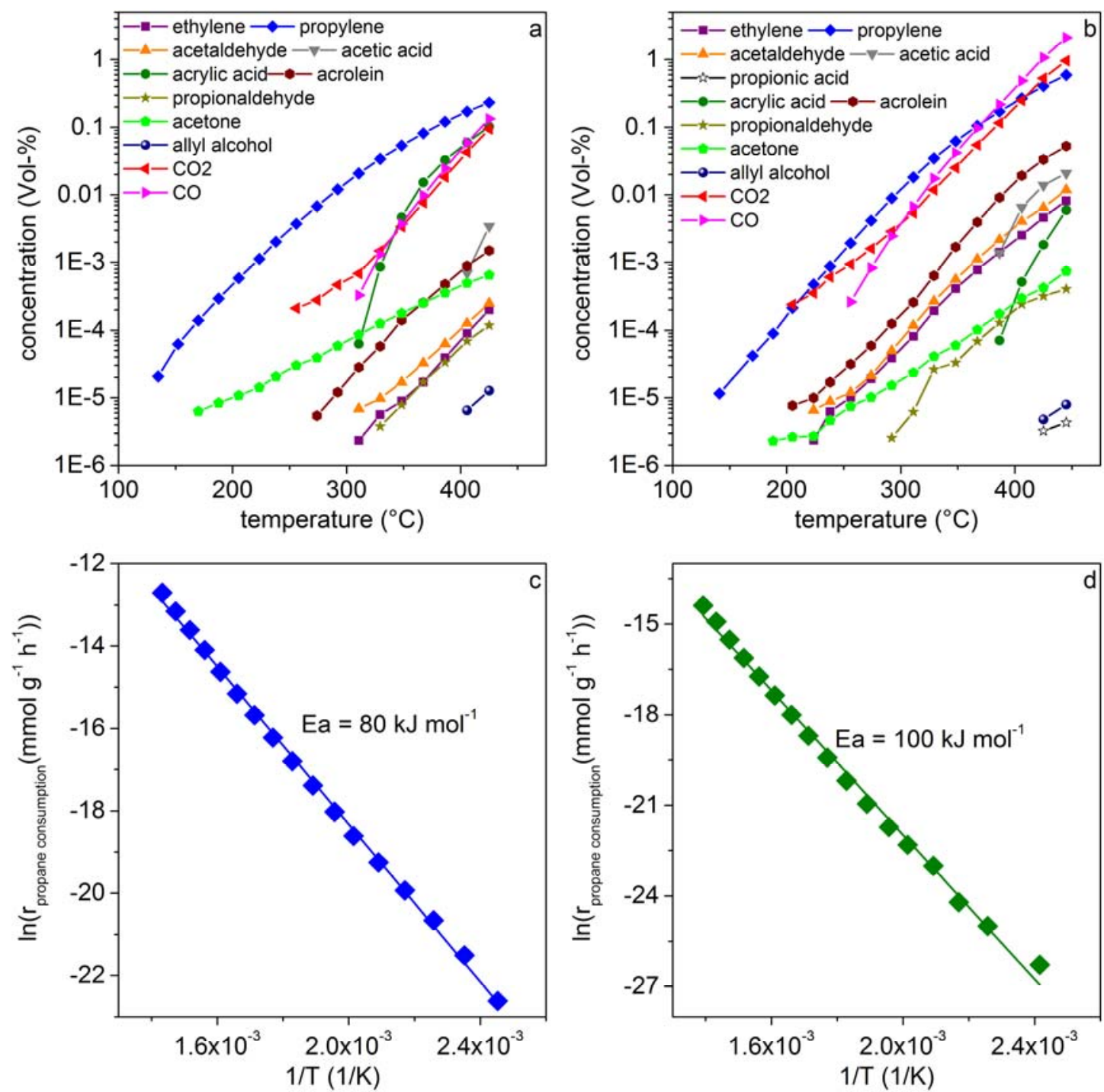

Figure 1. a) Temperature-programmed oxidation of propane (heating rate $1 \mathrm{~K} / \mathrm{min}$, measurement isothermal every $20 \mathrm{~K})$ over a) $\mathrm{M} 1\left(\mathrm{C}_{3} \mathrm{H}_{8} / \mathrm{O}_{2} / \mathrm{He}=10 / 5 / 85, \mathrm{~W} / \mathrm{F}=\right.$ $\left.0.06 \mathrm{~g} \mathrm{~s} \mathrm{ml}^{-1}, \mathrm{~m}_{\text {cat }}=10 \mathrm{mg}, \mathrm{F}_{\text {total }}=10 \mathrm{ml} \mathrm{min}^{-1}\right)$, and b) $6 \mathrm{~V} / \mathrm{SBA}-15\left(\mathrm{C}_{3} \mathrm{H}_{8} / \mathrm{O}_{2} / \mathrm{He}=10 / 5 / 85, \mathrm{~W} / \mathrm{F}=1.33 \mathrm{~g} \mathrm{~s} \mathrm{ml}^{-1}, \mathrm{~m}_{\text {cat }}=222 \mathrm{mg}, \mathrm{F}_{\text {total }}=10 \mathrm{ml} \mathrm{min}^{-1}\right) ;$ Arrhenius plots measured over M1 (c) and 6V/SBA-15 (d) taking into account the overall rate of propane consumption calculated based on sum of the reaction products. 
The primary formation of carbon oxides (without desorption of reaction intermediates) cannot be excluded based on the present experiments. Indication for the latter process has been found on $\mathrm{M} 1,{ }^{[8]}$ and supported vanadium oxide catalysts. ${ }^{[10]}$ Here, the propylene selectivity increases with increasing vanadia loading, which has been attributed to coverage of unselective support sites, ${ }^{[10]}$ or to the higher activity, ${ }^{[10 b]}$ and/or a modified reducibility ${ }^{[10 a]}$ of supported polyvanadate species.

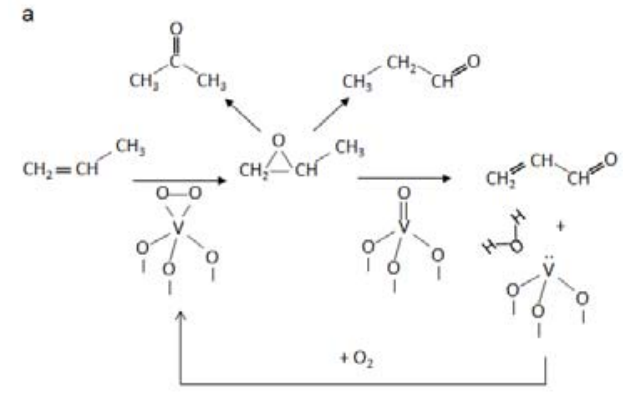

b

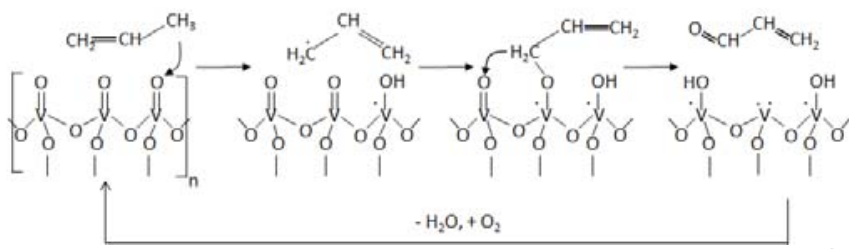

Scheme 2. Low-temperature (a) and high-temperature (b) formation of acrolein, acetone and propionaldehyde; Low-temperature oxidation via propylene oxide occurs mainly on silica-supported vanadium oxide; High-temperature allylic oxidation occurs on both $\mathrm{M} 1$ and silica-supported vanadium oxide and requires at least $\mathrm{V}_{\mathrm{x}} \mathrm{O}_{\mathrm{y}}$ trimers

Acrolein also starts to form already at $200^{\circ} \mathrm{C}$ over 6 V/SBA- 15 . Acrolein formation occurs here together with $\mathrm{CO}_{2}$ and with a temperature offset of $+20 \mathrm{~K}$ with respect to acetone. Propylene oxide has been proposed as a common intermediate in the formation of acrolein and acetone in density functional calculations applying silsesquioxane models, ${ }^{[2]}$ considering either isolated vanadyl surface groups or peroxovanadate species as active sites. Although propene oxide has not been detected in the gas phase in the present experiment, the nearly simultaneous appearance of acetone and acrolein over 6V/SBA-15 is not in contradiction with such pathways. In contrast, over M1 the two products arise at very different temperatures. While acetone appears first at $160^{\circ} \mathrm{C}$ on $\mathrm{M} 1$, acrolein is observed only at $270^{\circ} \mathrm{C}$ with an offset of $+70 \mathrm{~K}$ compared to $6 \mathrm{~V} / \mathrm{SBA}-15$. The slope of the acrolein formation curve measured for $6 \mathrm{~V} / \mathrm{SBA}-15$ changes in the temperature range in which acrolein formation sets in over M1. It might be, therefore, possible that different mechanisms contribute to acrolein formation over 6V/SBA-15, such as a low-temperature $\left(200-300^{\circ} \mathrm{C}\right)$ oxidation pathway catalysed by activated oxygen species at the surface, such as peroxovanadate, via propylene oxide as intermediate followed by oxidative dehydrogenation (Scheme 2a), and the allylic oxidation of propylene at higher temperatures $\left(>300^{\circ} \mathrm{C}\right.$ ) (Scheme $2 \mathrm{~b}$ ). In the low-temperature range acetone and propionaldehyde may be formed as isomerization products of propylene oxide. ${ }^{[11]}$ Indications for the participation of peroxide species in oxidative dehydrogenation of propane over supported vanadium oxide catalysts have been found recently by experiment, ${ }^{[12]}$ and theory. ${ }^{[13]}$ Such a change in the shape of the acrolein formation curve is not observed over M1 which is in agreement with a low concentration of electrophilic oxygen species on the surface of $\mathrm{M} 1$ also at low temperatures resulting in the dominance of the allylic mechanism. ${ }^{[14]}$

It is interesting to note that the shapes of the $\mathrm{CO}_{2}$ evolution curves observed over $\mathrm{M} 1$ and $6 \mathrm{~V} / \mathrm{SBA}-15$, respectively, are very similar. The slopes of the curves change at $300^{\circ} \mathrm{C}$ indicating that at higher temperatures additional processes contribute to $\mathrm{CO}_{2}$ formation.

The next group of products comprises acetaldehyde, ethylene, and $\mathrm{CO}$ arising at $220^{\circ} \mathrm{C}$ (with an offset for $\mathrm{CO}$ of $+20 \mathrm{~K}$ perhaps due to the detection limit of the TCD detector) over 6V/SBA-15 and at $300^{\circ} \mathrm{C}$ over $\mathrm{M} 1$ revealing that also the disintegration of the carbon backbone occurs already at much lower temperature over 6V/SBA-15 compared to M1. Decomposition pathways are not directly retrievable from the present experiment. It is interesting to note that over M1 the appearance of acetaldehyde, ethylene and $\mathrm{CO}$ coincide with acrylic acid formation, whereas a temperature difference of about $200 \mathrm{~K}$ is observed over $6 \mathrm{~V} / \mathrm{SBA}-15$ between first detection of these products and the formation of acrylic acid. The reason might be that acetaldehyde is a common intermediate that may be formed starting from acetone, acrolein, ${ }^{[15]}$ as well as acrylic acid (Scheme 3, Scheme S1). In particular, the decomposition pathways of acrolein to $\mathrm{CO}_{x}$ and acrylic acid to ethylene and $\mathrm{CO}_{x}$ may share a joint $\mathrm{C} 2$ surface intermediate (Scheme 3, Scheme S1).

The shapes of the acrylic acid evolution curves (steep slope) are comparable over the two catalysts. Formation starts at $400^{\circ} \mathrm{C}$ over 6V/SBA-15. The curve is shifted by $100 \mathrm{~K}$ to lower temperatures over $\mathrm{M} 1$ indicating that in contrast to other oxygenates formation of acrylic acid is particularly facilitated over M1.

Acetic acid occurs only above $400^{\circ} \mathrm{C}$ over both catalysts and the curves progress in parallel to the acrylic acid formation curves confirming previous results that acetic acid might be formed by decomposition of acrylic acid. ${ }^{[8]}$ But it cannot be excluded that acetic acid is also formed by oxidation of adsorbed $\mathrm{C} 2$ precursors formed in acrolein decomposition (Scheme 3, Scheme S1). C2 and C3 precursors are then apparently oxidized to the corresponding acids in the same temperature range. Acetic acid could also be formed by oxidation of re-adsorbed ethylene, which is formed in C-C bond splitting reactions that occur already at lower temperatures (see ethylene evolution curves in Fig. 1). However, this is less likely, since the slope of the ethylene evolution curves are not affected by the onset of acetic acid formation (Fig. 1). Acrylic acid is either more slowly formed or faster decomposed to acetic acid over 6V/SBA-15 compared to $\mathrm{M} 1$, because over the former catalyst the concentration of acetic acid is higher than the concentration of acrylic acid whereas the reverse situation is observed over $\mathrm{M} 1$.

Remarkably, allyl alcohol, which is an intermediate of propene allylic oxidation, is still detectable over both catalysts at temperatures above $400^{\circ} \mathrm{C}$ when the molecule reaches sufficient high concentration in the gas phase revealing that allylic oxidation is a common pathway over both catalysts.

Finally, a pathway via adsorbed $n$-propoxide resulting in propionaldehyde (occurrence above $300^{\circ} \mathrm{C}$ ) and propionic acid 
(detectable only over 6V/SBA-15 above $400^{\circ} \mathrm{C}$ ) is operative over both catalysts as well. Formation of propionaldehyde at low temperature by isomerization of propylene oxide cannot be excluded.

The rate of overall propane consumption calculated based on the sum of products has been plotted as a function of $1 / T$ (Figs. $1 \mathrm{c}-\mathrm{d})$. The function is overall linear for both catalysts $\left(R^{2}=0.9985\right.$ for $\mathrm{M} 1$, and $\mathrm{R}^{2}=0.9949$ for $6 \mathrm{~V} / \mathrm{SBA}-15$ ) indicating that significant changes in the reaction network do not occur in the studied temperature range at points where new products appear in the gas phase meaning that all detected products might belong to a single complex reaction network branching out from propane. Slight deviation occurs at low temperatures over 6V/SBA-15 for the reasons discussed above (Scheme 2). The apparent activation energies (Figs. 1c-d) agree well with published values for $\mathrm{M} 1^{[4,8]}$ and SBA-15-supported vanadium oxide, ${ }^{[16]}$ respectively.

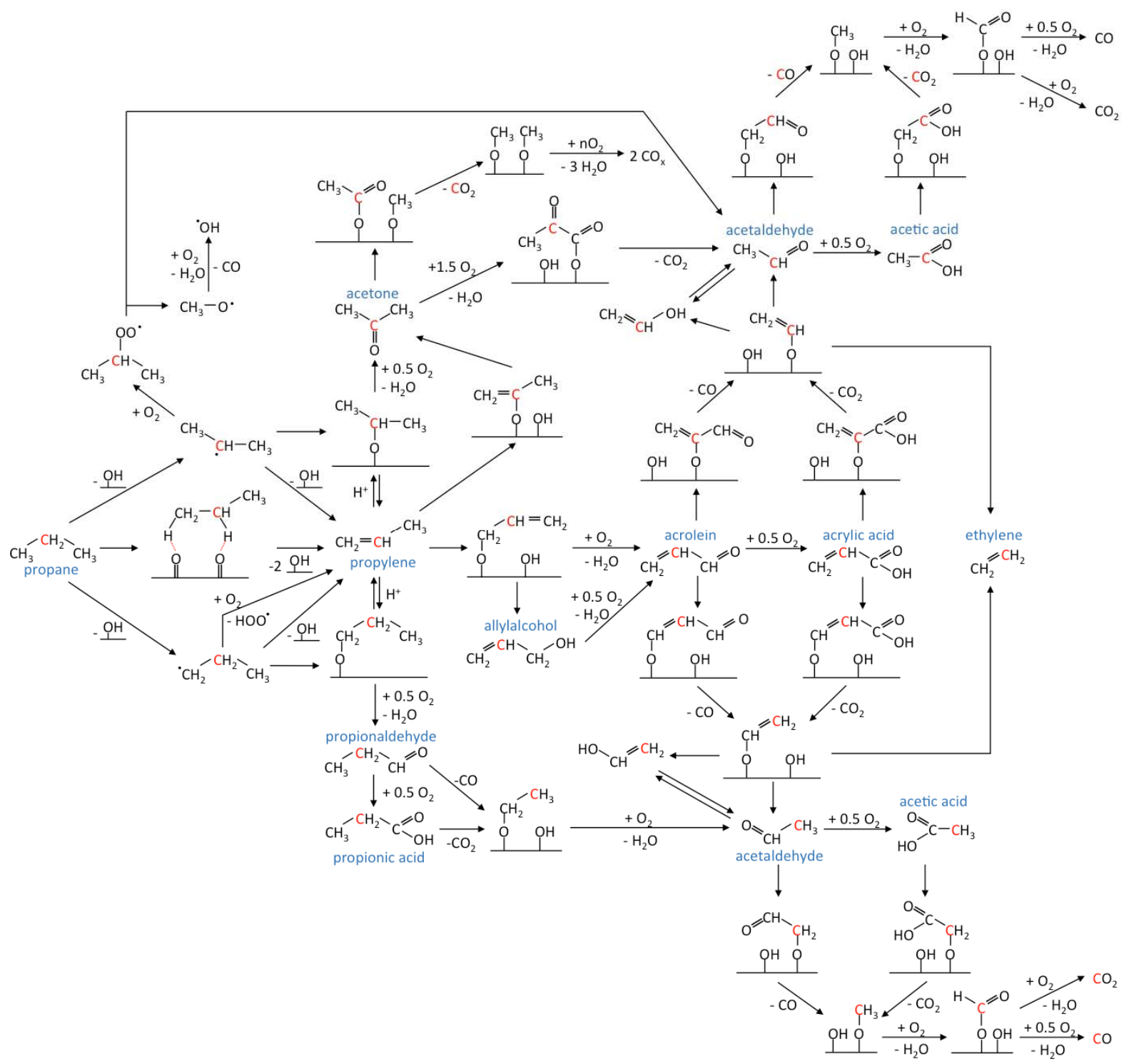

Scheme 3. Reaction network in propane oxidation outlined based on intermediate products detected in the gas phase (blue) over M1 and $6 \mathrm{~V} / \mathrm{SBA}-15$ in dry feed $\left(\mathrm{C}_{3} \mathrm{H}_{8} / \mathrm{O}_{2} / \mathrm{He}=10 / 5 / 85\right)$ in the temperature range $100-450^{\circ} \mathrm{C}$ during temperature-programmed propane oxidation; Furthermore, the results of the experiments with $\mathrm{D}$ and ${ }^{13} \mathrm{C}$-labelled propane (the red colour indicates the ${ }^{13} \mathrm{C}$-labelled carbon atom) have been integrated into the Scheme; $\mathrm{A}$ version of the Scheme that highlights major principal similarities and differences in the reaction networks over 6V/SBA-15 and M1 is presented in the Supporting Information ( Scheme S1).

In summary, the temperature-programmed experiments reveal that a multitude of reaction products (11 over $\mathrm{M} 1$ and 12 over 6V/SBA-15) are detectable by gas chromatography in the temperature range $100-450^{\circ} \mathrm{C}$ and consequently involved in the reaction network of propane oxidation over both, M1 and 6V/SBA15 catalysts. A hypothetical reaction network that includes all intermediates detected so far in the gas phase under the specific reaction conditions applied in the present experiments is presented in Scheme 3. The experimentally proven reaction intermediates are highlighted in blue. Surface intermediates have been proposed based on spectroscopic studies of selective and total oxidation catalysts. ${ }^{[17]}$ The type of products detected and the shape of the product evolution curves are strikingly similar at normal reaction temperatures of propane oxidation $\left(300-400^{\circ} \mathrm{C}\right)$ suggesting that the same global reaction network predominates over the two catalyst systems, but the rate constants of individual 
reaction steps differ. However, at temperatures below $300^{\circ} \mathrm{C}$ differences are observed in particular with respect to acrolein formation. Hydrogen-abstraction under formation of propylene occurs already at very low temperature over both catalysts followed by oxyhydration/oxidation to acetone or allylic oxidation to acrolein. Acrolein formation and cleavage of $\mathrm{C}-\mathrm{C}$ bonds are reactions particularly favoured over $6 \mathrm{~V} / \mathrm{SBA}-15$, while acrylic acid formation is favoured over M1.

Based on the assumption that the entire reaction network in propane oxidation over M1 and 6V/SBA-15 is similar, differences in the selectivity of the overall reaction result from differences in the activation energy of individual reaction steps. In the following, we have analysed kinetic isotope effects (KIE) based on rates of overall propane consumption and propylene formation. If the abstraction of the first hydrogen atom in adsorbed propane is rate limiting, the rate of propane consumption must be affected by deuteration. To verify whether hydrogen abstraction in methylene position is the rate-limiting step of the overall propane oxidation, propane consumption rates were measured using $\mathrm{C}_{3} \mathrm{H}_{8}$ and 2,2$\mathrm{C}_{3} \mathrm{D}_{2} \mathrm{H}_{6}$, respectively. Similarly, the impact of splitting a $\mathrm{C}-\mathrm{H}$ bond in methyl position was studied comparing $2,2-\mathrm{C}_{3} \mathrm{D}_{2} \mathrm{H}_{6}$ and $\mathrm{C}_{3} \mathrm{D}_{8}$, respectively. Rates extrapolated to zero conversion determined in contact time variations at $\mathrm{T}=400^{\circ} \mathrm{C}$ (Figs. S2-S3) have been used (Tab. 1) to calculate the KIE (Tab. 2).

In agreement with isotope studies of propane $\mathrm{ODH}$ over zirconia supported vanadium oxide catalysts, ${ }^{[6]}$ the substitution of $\mathrm{H}$ by $\mathrm{D}$ in methylene position affects the overall consumption rate of the substrate over 6V/SBA-15 (Tab. 1) resulting in a significant KIE of 1.45 (Tab. 2) and revealing that $\mathrm{C}-\mathrm{H}$ activation of methylene hydrogen in propane affects the propane consumption rate also over silica-supported vanadium oxide. Deuteration in methyl position has no effect resulting in a KIE of 1 again in agreement with the literature.

Table 1. Propane consumption rates, propylene formation rates, and selectivity to propylene over the two catalysts obtained in contact time variation experiments $\left(\mathrm{W} / \mathrm{F}=0.02-0.06 \mathrm{~g} \mathrm{~s} \mathrm{ml}^{-1}\right.$ for $\mathrm{M} 1$, and $0.30-1.34 \mathrm{~g} \mathrm{~s} \mathrm{ml}^{-1}$ for $6 \mathrm{~V} / \mathrm{SBA}-15$ ) in the feed $\mathrm{C}_{3} \mathrm{H}_{8} / \mathrm{O}_{2} / \mathrm{He}=10 / 5 / 85$ at $\mathrm{T}=400^{\circ} \mathrm{C}$ with different isotopes after extrapolation to zero propane conversion (raw data shown in the Supporting Information, Figs. S2-S3).

\begin{tabular}{lllll}
\hline catalyst & Reactant & \multicolumn{1}{r}{$\begin{array}{l}r_{\mathrm{C} 3,0^{*}} 10^{-7} \\
{\left[\mathrm{~mol} \mathrm{~g}^{-1} \mathrm{~s}^{-1}\right]}\end{array}$} & $\begin{array}{l}r_{\mathrm{C} 3=, 0^{*} 10^{-7}} \\
{\left[\mathrm{~mol} \mathrm{~g}^{-1} \mathrm{~s}^{-1}\right]}\end{array}$ & $S_{\mathrm{C} 3=0}$ \\
\hline \multirow{3}{*}{ 6V/SBA-15 } & $\mathrm{CH}_{3} \mathrm{CH}_{2} \mathrm{CH}_{3}$ & 1.86 & 1.61 & 87 \\
\cline { 2 - 5 } & $\mathrm{CH}_{3} \mathrm{CD}_{2} \mathrm{CH}_{3}$ & 1.25 & 0.94 & 75 \\
\cline { 2 - 5 } & $\mathrm{CD}_{3} \mathrm{CD}_{2} \mathrm{CD}_{3}$ & 1.24 & 0.33 & 27 \\
\hline \multirow{3}{*}{$\mathrm{M} 1$} & $\mathrm{CH}_{3} \mathrm{CH}_{2} \mathrm{CH}_{3}$ & 20.8 & 18.5 & 89 \\
\cline { 2 - 5 } & $\mathrm{CH}_{3} \mathrm{CD}_{2} \mathrm{CH}_{3}$ & 14.0 & 8.7 & 62 \\
\cline { 2 - 5 } & $\mathrm{CD}_{3} \mathrm{CD}_{2} \mathrm{CD}_{3}$ & 9.0 & 7.9 & 88 \\
\hline
\end{tabular}

In contrast, both, deuteration of the methylene as well as the methyl group affects the rate of propane consumption over the M1 catalyst resulting in a KIE for methylene of 1.49 and for methyl of 1.55 . In case of fully deuterated propane the rate is further decreased yielding an overall KIE of 2.31. This means that the hydrogen atoms in methylene as well as methyl position are simultaneously involved in the consumption of propane by rate determining process(es). Parallel formation of iso-propoxide that requires $\mathrm{C}-\mathrm{H}$ activation in methylene position and $n$-propoxide that requires $\mathrm{C}-\mathrm{H}$ activation in methyl position should not be responsible for the observed effect, since propionaldehyde is also formed over 6V/SBA-15 to a similar extent (compare Figs. 1a-b, and $\mathrm{S} 1$ ), but here the deuteration of the methyl group has no impact.

Table 2. Kinetic isotope effects (KIE) in propane consumption and propylene formation calculated based on the rates provided in Table 1.

\begin{tabular}{llll}
\hline Catalyst & Isotopes & $\mathrm{KIE}(\mathrm{C} 3)$ & $\mathrm{KIE}(\mathrm{C} 3=)$ \\
\hline \multirow{4}{*}{ 6VISBA-15 } & $\begin{array}{l}\mathrm{CH}_{3} \mathrm{CH}_{2} \mathrm{CH}_{3} / \\
\mathrm{CH}_{3} \mathrm{CD}_{2} \mathrm{CH}_{3}\end{array}$ & 1.49 & 1.72 \\
\cline { 2 - 4 } & $\begin{array}{l}\mathrm{CH}_{3} \mathrm{CD}_{2} \mathrm{CH}_{3} / \\
\mathrm{CD}_{3} \mathrm{CD}_{2} \mathrm{CD}_{3}\end{array}$ & 1.01 & 2.84 \\
\cline { 2 - 4 } & $\begin{array}{l}\mathrm{CH}_{3} \mathrm{CH}_{2} \mathrm{CH}_{3} / \\
\mathrm{CD}_{3} \mathrm{CD}_{2} \mathrm{CD}_{3}\end{array}$ & 1.50 & 4.87 \\
\hline \multirow{4}{*}{$\mathrm{M} 1$} & $\begin{array}{l}\mathrm{CH}_{3} \mathrm{CH}_{2} \mathrm{CH}_{3} / \\
\mathrm{CH}_{3} \mathrm{CD}_{2} \mathrm{CH}_{3}\end{array}$ & 1.49 & 2.13 \\
\hline & $\begin{array}{l}\mathrm{CH}_{3} \mathrm{CD}_{2} \mathrm{CH}_{3} / \\
\mathrm{CD}_{3} \mathrm{CD}_{2} \mathrm{CD}_{3}\end{array}$ & 1.55 & 1.10 \\
\hline & $\begin{array}{l}\mathrm{CH}_{3} \mathrm{CH}_{2} \mathrm{CH}_{3} / \\
\mathrm{CD}_{3} \mathrm{CD}_{2} \mathrm{CD}_{3}\end{array}$ & 2.34 \\
\hline
\end{tabular}

The results may be interpreted in terms of a different structure of the intermediate in propylene formation on M1 compared to $6 \mathrm{~V} / \mathrm{SBA}-15$ that leads to similar barriers for the abstraction of the first and the second hydrogen atom, respectively. For better illustration, the part of the reaction network (Scheme 3) that seems to predominate propylene formation is enlarged in Scheme 4 and the differences between M1 and 6V/SBA-15 are highlighted in blue and green, respectively. Over M1 the limiting case might be a simultaneous mechanism, which seems to be not unlikely over Mo oxide containing catalysts according to DFT calculations using $\mathrm{Mo}_{3} \mathrm{O}_{9}$ model clusters. ${ }^{[18]}$ Our experimental numbers agree well with calculated KIEs from a $2+4$ pathway in which both methyl and methylene $\mathrm{C}-\mathrm{H}$ bonds are simultaneously involved. However, the calculated barrier for the corresponding transition state $(48.3 \mathrm{kcal} / \mathrm{mol})$ is higher compared to the experimentally determined value of $34 \mathrm{kcal} / \mathrm{mol}^{\left[{ }^{[4]}\right.}$ The $2+4$ mechanism corresponds to a concerted heterolytic $\mathrm{C}-\mathrm{H}$ activation (two-electron process) in which all in all 6 electrons are involved simultaneously including both metal atom and oxygen atom of a $\mathrm{M}=\mathrm{O}$ species as active site. The one-electron hydrogen abstraction under formation of a radical is, however, the energetically most feasible pathway in propane activation over $\mathrm{Mo}_{3} \mathrm{O}_{9}$ model clusters, ${ }^{[18]}$ and also over vanadium oxide. ${ }^{[19]}$ Therefore, quasi-simultaneous $\mathrm{H}$-abstraction on neighbouring $\mathrm{M}=\mathrm{O}$ sites (Scheme 4) might be taken into consideration as an explanation for the KIEs measured over M1. Such a mechanism has not been studied by theory so far. The high density of propane adsorption sites on the surface of $\mathrm{M} 1^{[4]}$ might render such a mechanism possible. Interestingly, a high density of 
oxidising sites has been reported to favour propylene formation instead of $\mathrm{C}-\mathrm{C}$ bond cleavage reactions on vanadium-based oxides. ${ }^{[20]}$

Furthermore, we analysed the rates of propylene formation albeit interpretation of the corresponding data is less straightforward, since formation of propylene requires the abstraction of two hydrogen atoms that must occur via several elementary steps. Interestingly, the selectivity to propylene is affected in a different way by isotope labelling over 6V/SBA-15 and M1 (Tab. 1). Consecutive reactions of the formed propylene are neglected in the following discussion of the difference, since the selectivity to propylene $S_{c 3=, 0}$ was determined based on extrapolation to zero propane conversion. Still, parallel reactions of propane may affect propylene formation rates at zero conversion, but the selectivity of propylene approaches approximately $90 \%$ at $X=0 \%$ in the reaction of native propane over both catalysts due to parallel formation of $n$-propoxide and its further oxidation (Tab. 1). By using fully deuterated propane the selectivity to propylene drops to $27 \%$ compared to the reaction of native propane ( $87 \%$ propene selectivity) over $6 \mathrm{~V} / \mathrm{SBA}-15$. After abstraction of the first $\mathrm{D}$ atom in the reaction of $\mathrm{C}_{3} \mathrm{D}_{8}$, a $\mathrm{C}_{3} \mathrm{D}_{7}$ intermediate is formed on $6 \mathrm{~V} / \mathrm{SBA}-15$ that reacts in the second step either to fully deuterated propene by another $D$ abstraction at the neighbouring methyl group ( $k_{1}$ in Scheme 1$)$ or to undesired by-products via an unspecified pathway $\left(k_{2}\right.$ in Scheme 1). The ratio of the corresponding two rate constants determines the selectivity to propene in the isotope exchange experiments in the limiting case of zero per cent conversion of propane. The decrease in propylene selectivity in the conversion of fully deuterated propane over $6 \mathrm{~V} / \mathrm{SBA}-15$ points at a reaction pathway competitive to selective $C-D$ activation in the $C_{3} D_{7}$ intermediate, which is not decelerated by isotope exchange, i.e. which does not involve D-C bond splitting. Competitively, reactions with gas-phase oxygen via alkylperoxy and hydroperoxyalkyl radicals, ${ }^{[21]}$ or fast attack of adsorbed oxygen at the carbon backbone of $C_{3} D_{7}$ in the adsorbed state may occur (Scheme 4). By using $\mathrm{CH}_{3} \mathrm{CD}_{2} \mathrm{CH}_{3}$ instead of native propane the selectivity to propylene is only slightly affected over 6V/SBA-15 (Tab. 1), because only the first step from $\mathrm{CH}_{3} \mathrm{CD}_{2} \mathrm{CH}_{3}$ to $\mathrm{CH}_{3} \mathrm{CDCH}_{3}$, which determines activity, but not selectivity, involves $\mathrm{D}$ abstraction. Propylene is formed in the subsequent step by abstraction of $\mathrm{H}$ from the methyl group of the $\mathrm{CH}_{3} \mathrm{CDCH}_{3}$ intermediate, like in case of native propane. However, the $k_{1} / k_{2}$ ratio may be influenced by secondary isotope effects resulting in slightly diminished selectivity of $75 \%$ compared to $87 \%$ for native propane (Tab. 1). Trends in the KIE's determined based on propylene formation rates (Tab. 2) are in agreement with this view.

M1 exhibits a different behaviour indicating that only deuteration of the methylene $\mathrm{C}-\mathrm{H}$ bonds facilitates formation of undesired by-products (Tab. 1). As discussed above, the KIE determined over $\mathrm{M} 1$ based on propane consumption rates at zero conversion is invariant with regard to the methylene or methyl position. That means that complete deuteration of propane retards the overall reaction, but will not interfere the structure of the transition states and intermediates, which is reflected in equal selectivity to propylene for native propane $(89 \%)$ and fully deuterated propane $(88 \%)$ at zero propane conversion (Table 1$)$. Other than on $6 \mathrm{~V} / \mathrm{SBA}-15$, destruction of the carbon skeleton of the $\mathrm{C}_{3} \mathrm{D}_{7}$ intermediate does not occur preferentially. No change in the $k_{1} / k_{2}$ ratio (Scheme 1 ) is in agreement with a low concentration of electrophilic oxygen species and adsorbed oxygen on the surface of M1. The equal selectivity in the experiments with native and fully deuterated propane, respectively, also support that consecutive reactions of propylene (at least reactions that involve $\mathrm{C}-(\mathrm{H}, \mathrm{D})$ splitting, such as allylic oxidation) are indeed negligible under the applied boundary conditions of zero propane conversion. In contrast, selectivity decreases by $27 \%$ over M1 when propane is deuterated in 2position. The difference between $\mathrm{M} 1$ and $6 \mathrm{~V} / \mathrm{SBA}-15$ is easily plausible when a simultaneous $\mathrm{H}$-abstraction mechanism is assumed over M1 (Scheme 4), which is in agreement with the KIEs measured over $\mathrm{M} 1$ and the much higher number of propane adsorption sites on the surface of M1 compared to 6V/SBA-15..$^{[4]}$ Upon exchange of $H$ by $D$ in 2-position a simultaneous mechanism is no longer possible leading to faster abstraction of methyl hydrogen that results in the formation $n$-propyl species as precursor of saturated oxygenated products and carbon oxides (Schemes 3-4).

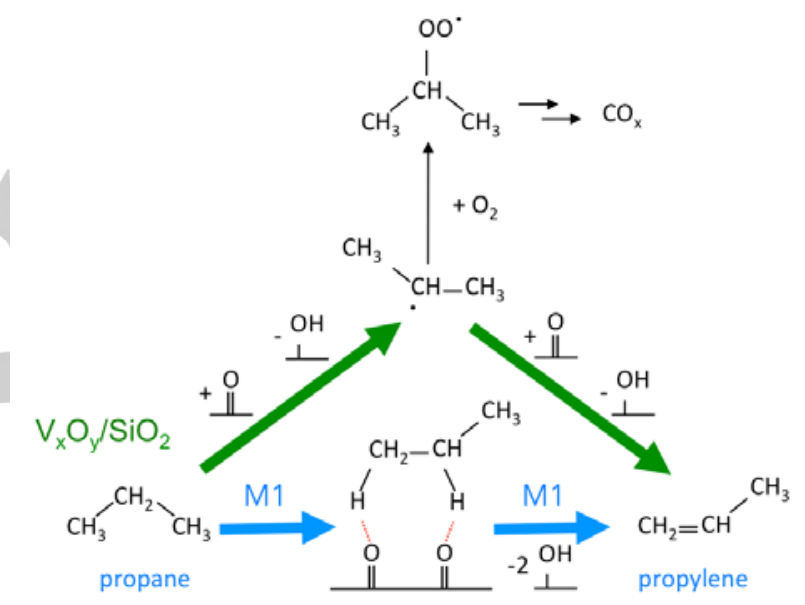

Scheme 4. Differences in the formation mechanism of propylene over silicasupported vanadium oxide (green) and M1 (blue) analysed based on KIE measurements.

Table 3. Propane conversion and product selectivity in dependence of steam addition (10 vol\%) to the feed at $400^{\circ} \mathrm{C}, \mathrm{W} / \mathrm{F}=0.06 \mathrm{~g} \mathrm{~s} \mathrm{ml}^{-1}(\mathrm{M} 1)$, and $1.34 \mathrm{~g}$ $\mathrm{s} \mathrm{ml}^{-1}(6 \mathrm{~V} / \mathrm{SBA}-15)$ and $\mathrm{C}_{3} \mathrm{H}_{8} / \mathrm{O}_{2} / \mathrm{He}=10 / 5 / 85$.

\begin{tabular}{|c|c|c|c|c|}
\hline & \multicolumn{2}{|l|}{ M1 } & \multicolumn{2}{|c|}{ 6V/SBA-15 } \\
\hline & $\mathrm{H}_{2} \mathrm{O}$ & $\mathrm{D}_{2} \mathrm{O}$ & $\mathrm{H}_{2} \mathrm{O}$ & $\mathrm{D}_{2} \mathrm{O}$ \\
\hline$X[\%]$ & 1.8 & 1.8 & 2.0 & 2.1 \\
\hline $\begin{array}{l}r_{\text {propane }} \quad \text { consumption, } 0 \\
\left(\mathrm{mmol} \mathrm{g}^{-1} \mathrm{~h}^{-1}\right)\end{array}$ & 4.81 & 4.82 & 0.247 & 0.255 \\
\hline S (propene) [\%] & 65.8 & 70.4 & 77.8 & 78.1 \\
\hline S (acrylic acid) [\%] & 30.0 & 25.0 & 0.2 & 0.2 \\
\hline S (acetic acid) [\%] & 1.3 & 1.5 & 5.3 & 5.2 \\
\hline $\mathrm{S}(\mathrm{C} 2)[\%]$ & 0.1 & 0.1 & 0.2 & 0.2 \\
\hline $\mathrm{S}(\mathrm{CO})[\%]$ & 2.0 & 2.2 & 9.9 & 9.7 \\
\hline $\mathrm{S}\left(\mathrm{CO}_{2}\right)[\%]$ & 0.8 & 0.9 & 6.7 & 6.7 \\
\hline
\end{tabular}


It should be noted that re-establishment of the active catalys surface after hydrocarbon oxidation (after first half of the catalytic cycle) can also influence the KIE. The rate constant for reoxidation of an oxygen vacancy on the catalyst surface, which is formed during formation of $\mathrm{H}_{2} \mathrm{O}$ from two $\mathrm{OH}$ groups, should be the same for (partially) deuterated and native propane. However, the (formal) rate constants of catalyst dehydration likely differ among each other depending on the degree of deuteration of the hydrocarbon substrate, as deuteration of the surface depends on the deuterium content of the substrate and dehydration of the surface in the final step of the catalytic cycle involves necessarily the cleavage of an O-H/O-D bond. The impact of catalyst reoxidation on the reaction rates was investigated by adding $\mathrm{H}_{2} \mathrm{O}$ or $\mathrm{D}_{2} \mathrm{O}$ to the feed of native propane and oxygen under steady state conditions to modify the concentration of surface $\mathrm{OH}$ or $\mathrm{OD}$ groups (Tab. 3). Switching from $\mathrm{H}_{2} \mathrm{O}$ to $\mathrm{D}_{2} \mathrm{O}$ does not change the activity of both catalysts, indicating that catalyst dehydration does not affect KIEs obtained with deuterated propane. The selectivity pattern is not affected over 6V/SBA-15 in a measurable way. For $\mathrm{M} 1$, selectivity of acrylic acid is slightly higher in $\mathrm{H}_{2} \mathrm{O}$ compared to $\mathrm{D}_{2} \mathrm{O}$ at the expense of all other products. This indicates direct involvement of water in a kinetically relevant step of acrylic acid formation or vital $H / D$ exchange in the intermediate product propene, which results in deceleration of allylic oxidation as a consequence of the KIE for C-H/C-D bond cleavage. In any case the observation implies the existence of an additional kinetically relevant step in the reaction network, which is located within the path from propylene to acrylic acid.

The formation pathways of carbon oxides during propane oxidation were studied by means of pulse experiments with ${ }^{13} \mathrm{C}$ labelled/unlabelled propane/oxygen mixtures at $\mathrm{T}=400^{\circ} \mathrm{C}$. A schematic illustration of the experimental procedure is provided in the Supporting Information (Scheme S2). The applied labelled propane contains the ${ }^{13} \mathrm{C}$ atom in 2-position (labelled in red in Schemes 3,5$)$. The products of the pulse experiments were analysed by mass spectrometry after pre-separation of the product mixture into permanent gases $\left(\mathrm{CO}, \mathrm{CO}_{2}\right.$, and $\left.\mathrm{O}_{2}\right)$, hydrocarbons $\left(\mathrm{C}_{3} \mathrm{H}_{6}, \mathrm{C}_{3} \mathrm{H}_{8}\right)$, and acids by packed columns (for experiment description see Supporting Information). Propane conversion and product selectivity are summarized in Table 4. The conversion of propane has been adjusted for the two catalysts by choosing appropriate contact times. The conversion does not differ between native and ${ }^{13} \mathrm{C}$-2-propane. The propylene selectivity measured over the two catalysts was only slightly affected by isotope labelling.

In the experiments with the unlabelled reactant, $\mathrm{CO}$ and $\mathrm{CO}_{2}$ are formed in almost equal amounts with some excess of $\mathrm{CO}$, which is reflected in a selectivity ratio $\mathrm{CO} /\left(\mathrm{CO}+\mathrm{CO}_{2}\right)$ slightly greater than 0.5 (Table 4). The overall $\mathrm{CO} /\left(\mathrm{CO}+\mathrm{CO}_{2}\right)$ ratio changes only slightly when using labelled propane, resulting in values of 0.54 for $6 \mathrm{~V} / \mathrm{SBA}-15$ and 0.48 for M1. The observed deviations are within the error of carbon oxides detection. The proposed reaction network (Scheme 3) features a multitude of reaction pathways that finally yield both $\mathrm{CO}$ and $\mathrm{CO}_{2}$. But when the ${ }^{13} \mathrm{C}$-labelled reactant is pulsed, distinct differences in the origin of $\mathrm{CO}$ and $\mathrm{CO}_{2}$ over the two catalysts become obvious (Scheme 5).
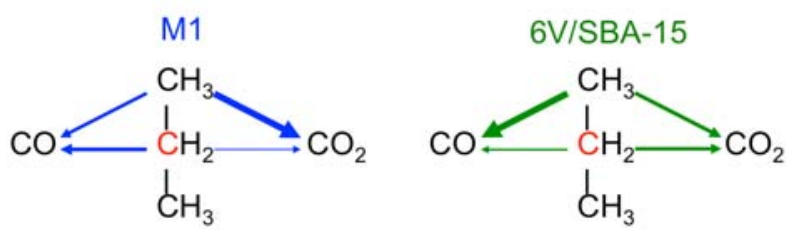

Scheme 5. Predominant origin of carbon oxides over M1 (blue) or 6V/SBA_15 (green); Line thickness of arrows reflects the selectivity presented in Table 4.

Over M1 the carbon in methylene position contributes slightly more to CO formation compared to the carbon in methyl position as indicated by the higher ${ }^{13} \mathrm{CO} /\left({ }^{13} \mathrm{CO}+{ }^{13} \mathrm{CO}_{2}\right)$ ratio of 0.75 , whereas $\mathrm{CO}_{2}$ preferentially originates from one of the terminal carbon atoms (Table 4, Scheme 5). The opposite pattern is observed over $6 \mathrm{~V} / \mathrm{SBA}-15$, i.e., CO originates mainly from the methyl position and $\mathrm{CO}_{2}$ from the methylene position, respectively

The observation that the majority of $\mathrm{CO}_{2}$ formed over $\mathrm{M} 1$ is unlabelled indicates that the $\mathrm{C}_{3}$ intermediate to $\mathrm{CO}_{2}$ predominantly bears a terminal functional group that contains two oxygen atoms (e.g., a carboxylic acid group). The C3 acid is acrylic acid, since propionic acid is not formed over M1 under the applied reaction conditions (Fig. 1a). The elimination of unlabelled $\mathrm{CO}_{2}$ (decarboxylation) from acrylic acid gives a residual $\mathrm{C} 2$ fragment.

Table 4. Propane conversion and product selectivity for native and ${ }^{13} \mathrm{C}$-substituted propane in propane oxidation in a feed of $\mathrm{C}_{3} \mathrm{H}_{8} / \mathrm{O}_{2} / \mathrm{He}=10 / 5 / 85$ at $\mathrm{T}=400{ }^{\circ} \mathrm{C} ; \mathrm{W} / \mathrm{F}$ $=0.06 \mathrm{~g} \mathrm{~s} \mathrm{ml}^{-1}(\mathrm{M} 1)$, and $1.34 \mathrm{~g} \mathrm{~s} \mathrm{ml}^{-1}(6 \mathrm{~V} / \mathrm{SBA}-15)$.

\begin{tabular}{|c|c|c|c|c|c|c|c|c|c|c|}
\hline Catalyst & $\begin{array}{l}\text { Reactant } \\
\left(\mathrm{C}_{3}\right)\end{array}$ & $\begin{array}{l}\text { Feed } \\
\mathrm{C}_{3} / \mathrm{O}_{2} / \mathrm{He}\end{array}$ & $\begin{array}{l}\mathrm{X}\left(\mathrm{C}_{3} \mathrm{H}_{8}\right) \\
{[\%]}\end{array}$ & $\begin{array}{l}\mathrm{S}\left(\mathrm{C}_{3} \mathrm{H}_{6}\right) \\
{[\%]}\end{array}$ & $\begin{array}{l}\mathrm{S}\left({ }^{12} \mathrm{CO}\right) \\
{[\%]}\end{array}$ & $\begin{array}{l}\mathrm{S}\left({ }^{12} \mathrm{CO}_{2}\right) \\
{[\%]}\end{array}$ & $\begin{array}{l}\mathrm{S}\left({ }^{13} \mathrm{CO}\right) \\
{[\%]}\end{array}$ & $\begin{array}{l}\mathrm{S}\left({ }^{13} \mathrm{CO}_{2}\right) \\
{[\%]}\end{array}$ & $\frac{S_{12} \mathrm{CO}}{S_{{ }^{12} \mathrm{CO}}+S^{12} \mathrm{CO}_{2}}$ & $\frac{S_{13} \mathrm{CO}}{\mathrm{S}_{{ }^{13} \mathrm{CO}}+S^{13} \mathrm{CO}_{2}}$ \\
\hline \multirow[t]{2}{*}{ M1 } & $\mathrm{C}_{3} \mathrm{H}_{8}$ & $10 / 5 / 85$ & 4.0 & 69.4 & 15.9 & 14.6 & - & - & 0.52 & - \\
\hline & ${ }^{13} \mathrm{C}-2-\mathrm{C}_{3} \mathrm{H}_{8}$ & $10 / 5 / 85$ & 4.0 & 68.1 & 7.2 & 13.8 & 8.2 & 2.8 & 0.34 & 0.75 \\
\hline \multirow[t]{2}{*}{ 6V/SBA-15 } & $\mathrm{C}_{3} \mathrm{H}_{8}$ & $10 / 5 / 85$ & 4.6 & 65.3 & 19.2 & 15.4 & - & - & 0.55 & - \\
\hline & ${ }^{13} \mathrm{C}-2-\mathrm{C}_{3} \mathrm{H}_{8}$ & $10 / 5 / 85$ & 4.5 & 62.8 & 15.3 & 9.1 & 4.7 & 8.2 & 0.63 & 0.36 \\
\hline
\end{tabular}

Acetaldehyde, labelled either at the carbonyl group or at the methyl carbon, and ethylene are the $\mathrm{C} 2$ products primary formed either from acrolein or acrylic acid (Scheme 3). As discussed above, ethylene might be a quite stable end product. Acetaldehyde can be either oxidized at the methyl group and subsequently decarbonylated to give adsorbed methoxy species 
or it is further oxidized to acetic acid by oxygen insertion into the $\mathrm{C}-\mathrm{H}$ bond of the $\mathrm{CHO}$ group. Acetaldehyde, which is labelled at the carbonyl group, yields labelled $\mathrm{CO}$ by decarbonylation and an unlabelled surface methoxy group. The latter may be oxidized to formate species, which finally form $\mathrm{CO}$ by decarbonylation or $\mathrm{CO}_{2}$ by decarboxylation, both unlabelled (Scheme 2, top).

The labelled ${ }^{13} \mathrm{C}$ atom in acetic acid formed over $\mathrm{M} 1$ is primarily located in the methyl group, as indicated by mass spectrometry (Fig. 2). The mass spectrum of pure native acetic acid (Fig. 2a) displays two major fragments corresponding to a carboxylate $\mathrm{CO}_{2} \mathrm{H}^{+}$species $(\mathrm{m} / \mathrm{z} 45)$ and a $\mathrm{CH}_{3} \mathrm{CO}^{+}$species $(\mathrm{m} / \mathrm{z}$ $43)$, which are also present in the pre-separated acetic acid fraction of the product mixture observed in oxidation of native propane (Fig. 2b). Peaks due to ${ }^{13} \mathrm{CH}_{3} \mathrm{CO}^{+}$or $\mathrm{CH}_{3}{ }^{13} \mathrm{CO}^{+}(\mathrm{m} / \mathrm{z} 44)$ $\mathrm{CO}_{2} \mathrm{H}^{+}(\mathrm{m} / \mathrm{z} 45)$ and ${ }^{13} \mathrm{CO}_{2} \mathrm{H}^{+}(\mathrm{m} / \mathrm{z} 46)$ are observed when labelled ${ }^{13} \mathrm{C}$-2-propane is pulsed. The measured intensity ratio of these three peaks can be simulated by a ${ }^{13} \mathrm{CH}_{3} \mathrm{CO}_{2} \mathrm{H}: \mathrm{CH}_{3}^{13} \mathrm{CO}_{2} \mathrm{H}$ ratio of $3: 1$ indicating preferred formation of acetic acid with the ${ }^{13} \mathrm{C}$ atom located at the methyl position. This means that either acrolein or acrylic acid is preferentially attacked at the terminal methylene group, but attack at the central carbon is also possible, but less likely.

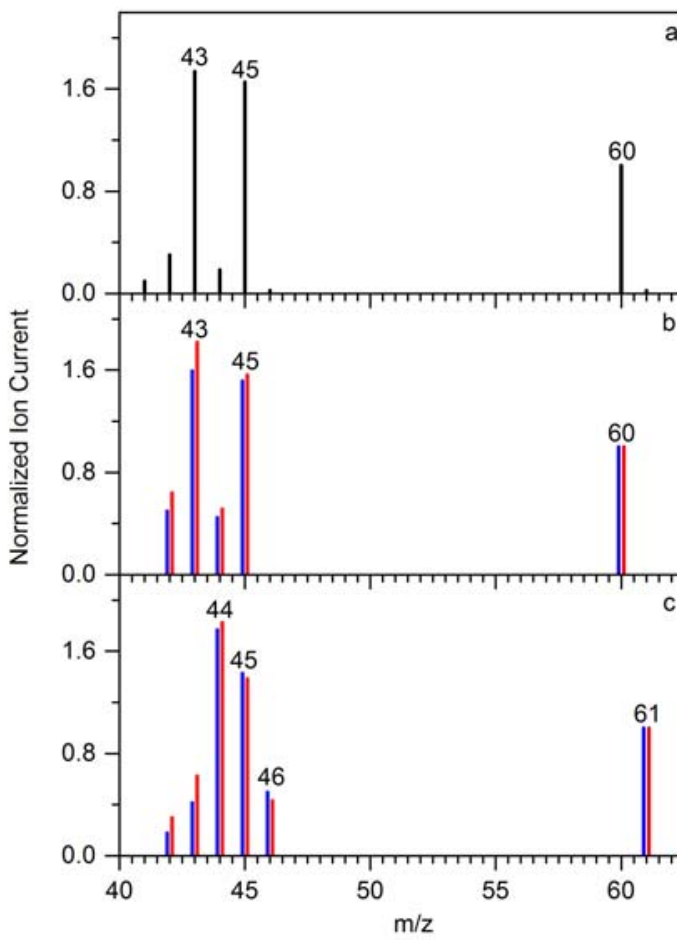

Figure 2. Mass spectrum of $2.6 \mathrm{vol}-\%$ acetic acid in He (a), mass spectrum of the acid fraction of the product mixture in the oxidation of native propane (b), and ${ }^{13} \mathrm{C}$-2-propane (c) on $\mathrm{M} 1$ at $\mathrm{T}=400{ }^{\circ} \mathrm{C}, \mathrm{W} / \mathrm{F}=0.3 \mathrm{~g} \mathrm{~s} \mathrm{ml}^{-1}$ and $\mathrm{C}_{3} / \mathrm{O}_{2} / \mathrm{He}=$ $20 / 5 / 75$ (blue) and $15 / 5 / 80$ (red); The propane content in the feed was increased in the corresponding experiments to increase the reliability of acetic acid analysis.

Acetic acid that contains a labelled methyl group releases unlabelled $\mathrm{CO}_{2}$ in a decarboxylation reaction. The residual labelled surface methoxy group is further oxidized to labelled $\mathrm{CO}$ or $\mathrm{CO}_{2}$, respectively (Scheme 2, bottom).

All decomposition reactions of the $\mathrm{C} 3$ oxygenates acrolein and acrylic acid outlined in Scheme 3 may occur in parallel, but the product distribution observed over M1 and 6V/SBA-15 in the temperature-programmed experiments (Fig. 1) and the distribution of the ${ }^{13} \mathrm{C}$ isotope in the final combustion products $\mathrm{CO}$ and $\mathrm{CO}_{2}$ (Table 4, Scheme 3) indicate differences in reaction rates of the individual steps. The high concentration of acrylic acid in the product mixture and the preferential formation of unlabelled $\mathrm{CO}_{2}$ suggest that over $\mathrm{M} 1$ oxidation of acrolein to acrylic acid via oxygen insertion into the $\mathrm{C}-\mathrm{H}$ bond of the $\mathrm{CHO}$ group is faster than oxidation of the vinyl group followed by decarbonylation of the resulting surface species and acetaldehyde formation. In contrast, decarbonylation of acrolein is preferred over 6V/SBA-15 as indicated by the increased fraction of unlabelled $\mathrm{CO}$. For clarity, the corresponding section of Scheme 3 is enlarged in Scheme 6 and the major differences between M1 (blue) and silica-supported vanadium oxide (green) are highlighted.

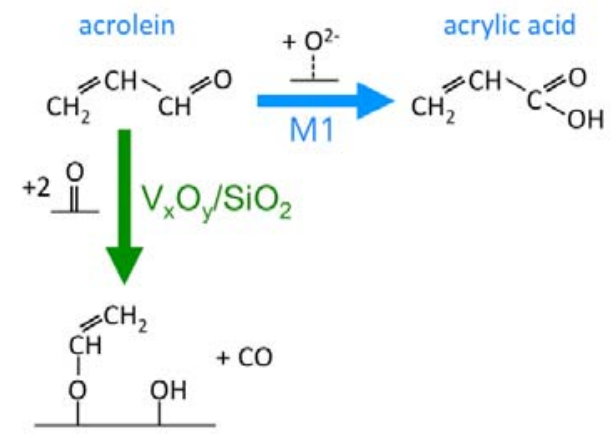

Scheme 6. Major differences in consecutive reactions of acrolein over M1 (blue) and 6V/SBA-15 suggested by the distribution of ${ }^{13} \mathrm{C}$ in the formed carbon oxides.

Similarly, over M1 the common intermediate acetaldehyde seems to be faster oxidized at the $\mathrm{CHO}$ group under formation of acetic acid. In contrast, over 6V/SBA-15 the methyl group of acetaldehyde is faster oxidized followed by decarbonylation of the corresponding surface intermediate.

An interpretation of the increased abundance of labelled $\mathrm{CO}_{2}$ over $6 \mathrm{~V} / \mathrm{SBA}-15$ is less straightforward. The decomposition of adsorbed acetone may contribute more significantly to labelled $\mathrm{CO}_{2}$ over $6 \mathrm{~V} / \mathrm{SBA}-15$, whereas acetone formed over $\mathrm{M} 1$ is more stable. In addition, differences in the decomposition of the final surface formate (Scheme 2, bottom right) either via decarboxylation or decarbonylation may contribute to the observed pattern.

\section{Summary and Conclusions}

In summary, the measurement of kinetic isotope effects in propane oxidation revealed essential differences in the activation of the propane molecule over M1 and silica-supported 
vanadium oxide, respectively. Whereas over silica-supported vanadium oxide the abstraction of the first hydrogen atom at the methylene group of the $\mathrm{C}_{3} \mathrm{H}_{8}$ molecule is rate limiting, activation of propane over M1 clearly involves both, methyl and methylene groups, simultaneously in rate-limiting process(es). The difference has no significant impact on the network of consecutive reactions of the formed propylene, but it may explain the lower barrier measured over $M 1,{ }^{[4]}$ and the corresponding difference between $\mathrm{M} 1$ and $6 \mathrm{~V} / \mathrm{SBA}-15$ in propane consumption rate that comprises one order of magnitude. ${ }^{[4]}$ At usually applied reaction temperatures (300$400^{\circ} \mathrm{C}$ ) the overall reaction network in propane oxidation seems to be similar over silica-supported vanadium oxide and M1 with the allylic oxidation of propylene being the predominant pathway since the intermediate allylic alcohol has been detected over both catalysts. The final product of the allylic oxidation over M1 is acrylic acid, while the reaction essentially terminates with acrolein formation over silica-supported vanadium oxide. Acetone formation via oxihydration or oxidation of propylene is a minor parallel pathway. Carbon oxides are mainly formed by decomposition of the main selective oxidation products acrolein and acrylic acid, which are preferentially attacked at the terminal methylene group under formation of the common decomposition product acetaldehyde. Differences in the preferred degradation pathways of acetaldehyde have been revealed by pulse experiments using ${ }^{13} \mathrm{C}$-2-propane. Over silica-supported vanadium oxide acetaldehyde seems to be preferentially oxidized at the methyl group followed by decarbonylation, whereas oxidation to acetic acid followed by decarboxylation is the favoured reaction path over M1.

The most important differences in the reaction network of propane oxidation under the studied conditions over the bulk catalyst M1 and the monolayer catalyst $6 \mathrm{~V} / \mathrm{SBA}-15$ have been detected in the formation mechanism of propylene (Scheme 4) and in the consecutive reaction of acrolein (Scheme 6). The differences in the reaction network over the two catalysts originate from differences in the surface concentration and distribution of oxygen species under reaction conditions. Based on the temperature-programmed experiments the formed products can be classified into olefins, carbonyl compounds, and acids. Propylene is formed at very low temperatures indicating clearly that the strength of the $\mathrm{C}-\mathrm{H}$ bond is no particular hurdle in propane activation in general. The result is in contrast to the popular opinion in oxidation catalysis that the thermodynamic stability of $\mathrm{C}-\mathrm{H}$ bonds in substrate molecules and intermediates determines the selectivity. ${ }^{[22]}$ Homolytic hydrogen abstraction has been proposed to be the favoured reaction path in propane activation over vanadium oxide. ${ }^{[19,23]}$ The activation requires nucleophilic oxygen and the vanadyl oxygen has been considered to be the most active one. ${ }^{[19 b, 19 c]}$ The formation of acrolein as the major carbonyl compound in the product mixture occurs also at comparatively low temperatures perhaps via attack of propylene by electrophilic oxygen species, which seem to be more abundant on the surface of silica-supported vanadium oxide compared to $\mathrm{M} 1$ due to the different electronic structure of the two catalysts as outlined in detail recently. ${ }^{[4]}$ Finally, formation of acids requires particularly high temperatures, especially over silica-supported vanadium oxide.
This implies that oxygen atoms, which are part of surface oxide species, are involved in the corresponding reaction.

Our results confirm that control over occurrence and distribution of the various oxygen species on the surface of vanadium oxide catalysts is the key issue in terms of selectivity. Selective oxidative dehydrogenation of propane to propylene requires the suppression of any electrophilic oxygen species on the catalyst surface, which might be solved by pulsed operation under alternate oxidizing and reducing conditions. ${ }^{[2]}$ The implementation of selective acrolein formation is more challenging, because it requires electrophilic oxygen species and faces the competitive oxidation of propylene in 2-position under formation of acetone and the consecutive oxidation to acetaldehyde that occur in the same temperature range. A more detailed analysis of the impact of reaction parameters on the rates within the network is required to find solutions. The formation of acrylic acid may be controlled via appropriate design of the solid-state chemistry of the catalysts in terms of oxygen species that selectively insert into the $\mathrm{C}-\mathrm{H}$ bond of a terminal $\mathrm{CHO}$ group. At this point we refer to the difference between silica-supported vanadium oxide and M1 in the onset temperature of acrylic acid formation. However, high selectivity to acrylic acid requires in addition and primarily the optimization of acrolein formation as well as the suppression of consecutive reactions such as the oxidative attack at the $\mathrm{CH}_{2}$ group of acrylic acid.

\section{Experimental Section}

\section{Catalysts}

Synthesis, and detailed bulk as well as surface analysis of the two catalysts have been described elsewhere. ${ }^{[4]}$

\section{Propane oxidation experiments}

Catalytic measurements were carried out in a self-constructed reactor setup with plug-flow characteristics using 10 or $50 \mathrm{mg}$ (M1) and $223 \mathrm{mg}$ (6V/SBA-15) catalyst. SiC was used to dilute the M1 catalyst for adjusting the same bed length as for 6V/SBA-15. The reactor (inner diameter 4 $\mathrm{mm}$ ) was equipped with a thermocouple for measuring the temperature inside the catalyst bed. $\mathrm{C}_{3} \mathrm{H}_{8}$ (Westfalen), $\mathrm{C}_{3} \mathrm{D}_{8}$ (Campro Scientific 99 atom\% D, Sigma Aldrich 99 atom\% D), 2,2- $\mathrm{C}_{3} \mathrm{D}_{2} \mathrm{H}_{6}$ (Sigma Aldrich 98 atom\% D), ${ }^{13} \mathrm{C}$-2-propane (ICON Isotopes 99 atom $\%{ }^{13} \mathrm{C}$ ), $\mathrm{O}_{2}$ (Westfalen) were used as reactants. The product gas mixtures were analyzed by online gas chromatography (Agilent 7890) and online mass spectrometry (QMA 400, Pfeiffer Vacuum). Separation of the gas pulses during ${ }^{13} \mathrm{C}-2-$ propane experiments were achieved by using a self packed column (Porapak $^{\text {TM }}$ Type Q 100-120 Mesh or Carbopack ${ }^{\mathrm{TM}}$ B-DA 80-120 Mesh) located between reactor outlet and analytics. More details concerning the performed experiments are provided in the Supporting Information (Scheme S2 und corresponding explanation). Starting and reference point for all measurements were a reaction temperature of $400^{\circ} \mathrm{C}$ and a dry feed of $10 \%$ native propane, $5 \%$ oxygen and $85 \% \mathrm{He} . \mathrm{H}_{2} \mathrm{O}$ and $\mathrm{D}_{2} \mathrm{O}$ (Sigma Aldrich 99.9 atom \% D) were introduced into the reactant stream via vaporizer at $140^{\circ} \mathrm{C}$. The calculation of propane conversion and product selectivity includes a correction for gas impurities in the initial gas mixture (namely labelled propylene in labelled propanes). Isotopic scrambling in propane in the gas phase as well as H/D exchange with the catalyst surface can be neglected (Supporting Information, Fig. S5). 


\section{Acknowledgements}

This work was conducted in the framework of the BasCat collaboration between BASF SE, TU Berlin, FHI, and the cluster of excellence "Unified Concepts in Catalysis" (UniCat www.unicat.tu-berlin.de)

Keywords: propane $\cdot$ oxidation $\cdot$ reaction network $\cdot$ kinetic isotope effect $\bullet$ vanadium oxide

[1] $\quad{ }^{\mathrm{a}} \mathrm{C}$. Coperet, Chemical Reviews 2010, 110, 656-680; ${ }^{\mathrm{b}} \mathrm{C}$. A. Gärtner, A. C. van Veen, J. A. Lercher, ChemCatChem 2013, 5, 3196-3217.

[2] aM. M. Bettahar, G. Costentin, L. Savary, J. C. Lavalley, Applied Catalysis, A: General 1996, 145, 1-48; 'b. L. Stern, R. K. Grasselli, Journal of Catalysis 1997, 167, 560-569; 'M. Lin, T. B. Desai, F. W. Kaiser, P. D. Klugherz, Catalysis Today 2000, 61, 223-229; ${ }^{\text {RR. Fushimi }}$ S. O. Shekhtman, A. Gaffney, S. Han, G. S. Yablonsky, J. T. Gleaves, Industrial \& Engineering Chemistry Research 2005, 44, 6310-6319; ' $\mathrm{R}$. Grabowski, Catalysis Reviews: Science and Engineering 2006, 48, 199 - 268; ${ }^{\mathrm{A}} \mathrm{A}$. Trunschke, in Nanostructured Catalysts: Selective Oxidation Reactions, 1 ed. (Eds.: C. Hess, R. Schlögl), RSC Nanoscience \& Nanotechnology, Cambridge, 2011, pp. 56-95; 9K. Alexopoulos, M.-F. Reyniers, G. B. Marin, Journal of Catalysis 2012, 289, 127-139; ' $\mathrm{K}$. Alexopoulos, M.-F. Reyniers, G. B. Marin, Journal of Catalysis 2012 295, 195-206; 'J. Liu, F. Mohamed, J. Sauer, Journal of Catalysis 2014 $317,75-82$.

[3] K. Chen, A. T. Bell, E. Iglesia, The Journal of Physical Chemistry B 2000, 104, 1292-1299.

[4] P. Kube, B. Frank, S. Wrabetz, J. Kröhnert, M. Hävecker, J. VelascoVélez, J. Noack, R. Schlögl, A. Trunschke, ChemCatChem 2017, 9 573-585.

[5] ${ }^{\mathrm{a}} \mathrm{C}$. A. Carrero, R. Schloegl, I. E. Wachs, R. Schomaecker, ACS Catalysis 2014, 4, 3357-3380; ' '. Muylaert, P. Van Der Voort, Physical Chemistry Chemical Physics 2009, 11, 2826-2832; cC. Hess ChemPhysChem 2009, 10, 319-326; 'F. Cavani, N. Ballarini, A. Cericola, Catalysis Today 2007, 127, 113-131; ' B. M. Weckhuysen, D. E. Keller, Catalysis Today 2003, 78, 25-46.

[6] K. Chen, E. Iglesia, A. T. Bell, Journal of Catalysis 2000, 192, 197-203.

[7] P. C. Redfern, P. Zapol, M. Sternberg, S. P. Adiga, S. A. Zygmunt, L. A Curtiss, The Journal of Physical Chemistry B 2006, 110, 8363-8371.

[8] R. Naumann D'Alnoncourt, L. I. Csepei, M. Hävecker, F. Girgsdies, M. E. Schuster, R. Schlögl, A. Trunschke, Journal of Catalysis 2014, 311, 369-385.

[9] G.-L. Dai, Z.-H. Li, J. Lu, W.-N. Wang, K.-N. Fan, The Journal of Physical Chemistry C 2012, 116, 807-817.
[10] aX. Gao, J.-M. Jehng, I. E. Wachs, Journal of Catalysis 2002, 209, 43

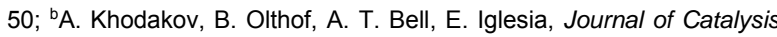
1999, 181, 205-216.

[11] Z. Zhai, X. Wang, R. Licht, A. T. Bell, Journal of Catalysis 2015, 325, 87-100.

[12] A. Held, J. Kowalska-Kuś, K. Nowińska, Journal of Catalysis 2016, 336, 23-32.

[13] V. I. Avdeev, A. F. Bedilo, Research on Chemical Intermediates 2016 42, 5237-5252.

[14] ${ }^{a}$ K. Amakawa, Y. V. Kolen'ko, A. Villa, M. E. Schuster, L.-I. Csepei, G. Weinberg, S. Wrabetz, R. Naumann d'Alnoncourt, F. Girgsdies, L. Prati R. Schlögl, A. Trunschke, ACS Catalysis 2013, 3, 1103-1113; 'b Sadovskaya, V. Goncharov, G. Popova, E. Ishchenko, D. Frolov, A. Fedorova, T. Andrushkevich, Journal of Molecular Catalysis A Chemical 2014, 392, 61-66; ' $\mathrm{C}$. Heine, M. Hävecker, M. SanchezSanchez, A. Trunschke, R. Schlögl, M. Eichelbaum, The Journal of Physical Chemistry C 2013, 117, 26988-26997.

[15] L. Bui, R. Chakrabarti, A. Bhan, ACS Catalysis 2016, 6, 6567-6580.

[16] A. Dinse, S. Khennache, B. Frank, C. Hess, R. Herbert, S. Wrabetz, R. Schlögl, R. Schomäcker, Journal of Molecular Catalysis A: Chemical 2009, 307, 43-50.

[17] aE. Finocchio, G. Busca, V. Lorenzelli, R. J. Willey, Journal of the Chemical Society, Faraday Transactions 1994, 90, 3347-3356; ' ${ }^{\mathrm{A}} \mathrm{A}$ A Davydov, Molecular spectroscopy of oxide catalyst surfaces, John Wiley \& Sons Ltd., Chinchester, 2003; ' P. Concepción, P. Botella, J. M. L. Nieto, Applied Catalysis A: General 2004, 278, 45-56; ' 'Y. Wang, W. Zheng, F. Chen, X. Zhan, Applied Catalysis A: General 2008, 351, 75 81; 'D. Shee, G. Deo, Journal of Molecular Catalysis A: Chemical 2009 308, 46-55; fJ. M. Lopez Nieto, B. Solsona, P. Concepcion, F. Ivars, A Dejoz, M. I. Vazquez, Catalysis Today 2010, 157, 291-296; ' 'R. LopezMedina, I. Sobczak, H. Golinska-Mazwa, M. Ziolek, M. A. Banares, M. O. Guerrero-Perez, Catalysis Today 2012, 187, 195-200

[18] G. Fu, X. Xu, X. Lu, H. L. Wan, Journal of Physical Chemistry B 2005 109, 6416-6421.

[19] aH. Fu, Z.-P. Liu, Z.-H. Li, W.-N. Wang, K.-N. Fan, Journal of the

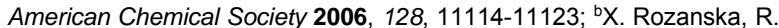
Fortrie, J. Sauer, The Journal of Physical Chemistry C 2007, 111, 60416050; cX. Rozanska, R. Fortrie, J. Sauer, Journal of the American Chemical Society 2014, 136, 7751-7761.

[20] E. V. Kondratenko, M. Y. Sinev, Applied Catalysis A: General 2007, 325, 353-361.

[21] J. Zádor, C. A. Taatjes, R. X. Fernandes, Progress in Energy and Combustion Science 2011, 37, 371-421.

[22] C. Batiot, B. K. Hodnett, Applied Catalysis A: General 1996, 137, 179 191.

[23] F. Gilardoni, A. T. Bell, A. Chakraborty, P. Boulet, Journal of Physical Chemistry B 2000, 104, 12250-12255.

[24] O. Ovsitser, R. Schomaecker, E. V. Kondratenko, T. Wolfram, A Trunschke, Catalysis Today 2012, 192, 16-19. 
Entry for the Table of Contents (Please choose one layout)

Layout 1:

\section{COMMUNICATION}

Roadmap to value or waste: The reaction network of propane oxidation over vanadium oxide catalysts was analysed by using temperatureprogrammed reactions and experiments with $\mathrm{D}$ - and ${ }^{13} \mathrm{C}$-labelled propane molecules. Propylene formation and oxidation of acrolein strongly depend on the nature of the catalyst. Surface density of vanadyl groups and nature of electrophilic oxygen species are relevant with regard to selectivity.

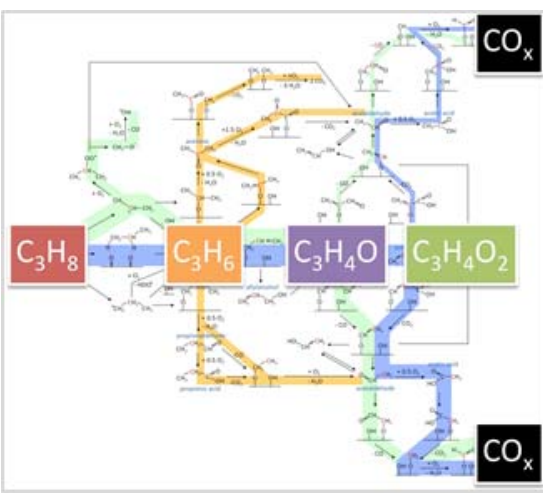

Pierre Kube, Benjamin Frank, Robert Schlögl, Annette Trunschke*

Page No. - Page No.

Isotope Studies in Oxidation of Propane over Vanadium Oxide 